\title{
Significance of Tissue Eosinophil in Unilateral Nasal Polyp
}

\author{
${ }^{1} \mathrm{P}$ Santoshu, ${ }^{2} \mathrm{~KB}$ Sunil Kumar, ${ }^{3} \mathrm{M}$ Divyashree, ${ }^{4} \mathrm{DR}$ Aravind
}

\begin{abstract}
Introduction: Nasal polyp is an inflammatory condition of unknown etiology with a prevalence rate of about $4 \%$. Unilateral nasal polyp is common in the ear, nose, and throat (ENT) practice and publications in the literature in this regard are few.

Aim: The aim of this study was histological analysis of eosinophil cells in unilateral nasal polyp and to correlate its relationship of allergic etiology with unilateral nasal polyp.
\end{abstract}

Materials and methods: The study conducted was a retrospective study where 70 patients diagnosed as unilateral nasal polyp were analyzed with their histopathology reports. It included patients of either sex with age between 6 and 65 years. All these patients had undergone surgery and polyp specimen was sent for histopathological examination.

The patients were grouped as per their histopathological diagnosis as inflammatory polyp with tissue eosinophil and inflammatory polyp without tissue eosinophil and were compared. Tissue eosinophil grading was done according to Shioda and Mishima system.

Data were analyzed and a conclusion was drawn.

Results: In total 70 patients (100\%) of unilateral nasal polyp, 33 patients $(47 \%)$ showed presence of tissue eosinophil and 37 patients $(53 \%)$ showed absence of tissue eosinophil in histopathological examination. Out of 33 patients with tissue eosinophil, 16 patients (48.5\%) showed significant tissue eosinophil with $\mathrm{p}<0.0000$.

Conclusion: Since the p-value is significant in our study, otorhinolaryngologists should consider allergy as an etiological factor in the management of unilateral nasal polyp.

Keywords: Allergy, Fisher's exact test, Inflammation.

How to cite this article: Santoshu P, Kumar KBS, Divyashree M, Aravind DR. Significance of Tissue Eosinophil in Unilateral Nasal Polyp. Int J Otorhinolaryngol Clin 2018;10(1):1-3.

Source of support: Nil

Conflict of interest: None

\section{INTRODUCTION}

Nasal polyp is an inflammatory condition of unknown etiology with a prevalence rate of about $4 \% .{ }^{1}$ Unilateral

\footnotetext{
${ }^{1}$ Professor, ${ }^{2}$ Associate Professor, ${ }^{3,4}$ Postgraduate Student

${ }^{1,3,4}$ Department of ENT, J.J.M Medical College, Davangere Karnataka, India

${ }^{2}$ Department of Pathology, J.J.M Medical College, Davangere Karnataka, India

Corresponding Author: P Santoshu, Professor, Department of ENT, J.J.M Medical College, Davangere, Karnataka, India Phone: +919845155223, e-mail: drsantoshup@gmail.com
}

nasal polyp presenting to ENT clinic is very common but there are very few literatures about this. The aim of this study is histological analysis of eosinophil cells in unilateral nasal polyp and to correlate its relationship of allergic etiology with unilateral nasal polyp.

\section{MATERIALS AND METHODS}

This retrospective study was conducted in Bapuji Hospital and Chigateri District Hospital, teaching hospital attached to J.J.M Medical College, Davangere, Karnataka, India. Seventy patients of unilateral nasal polyp were assessed by their histopathological reports. It included patients of either sex with age between 6 and 65 years.

All these patients had undergone surgery and polyp specimen was sent for histopathological examination. The patients were grouped as per their histopathological diagnosis as inflammatory polyp with tissue eosinophil and inflammatory polyp without tissue eosinophil, and they were compared.

Tissue eosinophils grading was done according to Shioda and Mishima system. ${ }^{2}$

- $\quad$ : occasional cells

- $\quad+$ : few natural cells

- ++ : moderate number of cells

- +++: clumps

IBM Statistical Package for the Social Sciences, version 20 for Windows was used for carrying out our statistical analysis. Mean and standard deviations were calculated for quantitative data; for categorical variables frequencies and percentages were calculated. The Fisher's test was used to analyze the two groups and it was tabulated; data were analyzed; and conclusion was drawn.

\section{RESULTS}

This retrospective study included a total of 70 patients (43 males and 27 females) (100\%) of unilateral nasal polyp during the period of January 2009 to November 2016. All 70 patients' polyp specimens were histopathologically diagnosed to be inflammatory polyp, out of which 33 patients $(47 \%)$ showed presence of tissue eosinophil and 37 patients (53\%) showed absence of tissue eosinophil (Table 1).

In our study, tissue eosinophils grading was done using the method of Shioda and Mishima system. According to grading, $(++)$ moderate number of eosinophil 
Table 1: Histopathology examination findings

\begin{tabular}{lll}
\hline Eosinophils & No. of cases & Percentage \\
\hline Present & 33 & 47 \\
Absent & 37 & 53 \\
\hline
\end{tabular}

Table 3: Fisher's exact test

\begin{tabular}{llll}
\hline Grading & $\begin{array}{l}\text { Without eosinophils } \\
(n=37)\end{array}$ & $\begin{array}{l}\text { With eosinophils } \\
(n=33)\end{array}$ & $\begin{array}{l}\text { Fisher's } \\
\text { exact test }\end{array}$ \\
\hline None & 37 & 17 & $\mathrm{p}<0.000$ \\
Significant & 0 & 16 & \\
\hline
\end{tabular}

cells and (+++) clumps of eosinophil cells were considered to be significant.

Histopathological examination of 33 patients of unilateral nasal polyp with tissue eosinophil was graded. Out of these 33 patients $(100 \%), 1$ patient $(3.0 \%)$ showed occasional cells, 16 patients (48.5\%) showed few natural cells, 5 patients $(15.2 \%)$ showed moderate number of cells, and 11 patients (33.3\%) showed clumps. A total of 16 patients $(48.5 \%)$ out of 33 patients $(100 \%)$ showed significant tissue eosinophil in unilateral nasal polyp (Table 2).

Unilateral nasal polyp with tissue eosinophil and unilateral nasal polyp without tissue eosinophil were later compared, using Fisher's exact test; p-value was found to be significant $(\mathrm{p}<0.000)$ (Table 3$)$.

\section{DISCUSSION}

Nasal polyp is defined as a prolapsed, edematous, and pedunculated nasal mucosa. There are two types of nasal polyps: Antrochoanal and ethmoidal polyp. Polypoidal tissue occupying the maxillary sinus nasal cavity and extending to choanae presenting as a single polyp is known as antrochoanal polyp (Fig. 1). ${ }^{3}$

Larsen and $\operatorname{Tos}^{4}$ in their study found benign unilateral nasal polyp as a condition that primarily affects young adults and children. In this study the incidence of

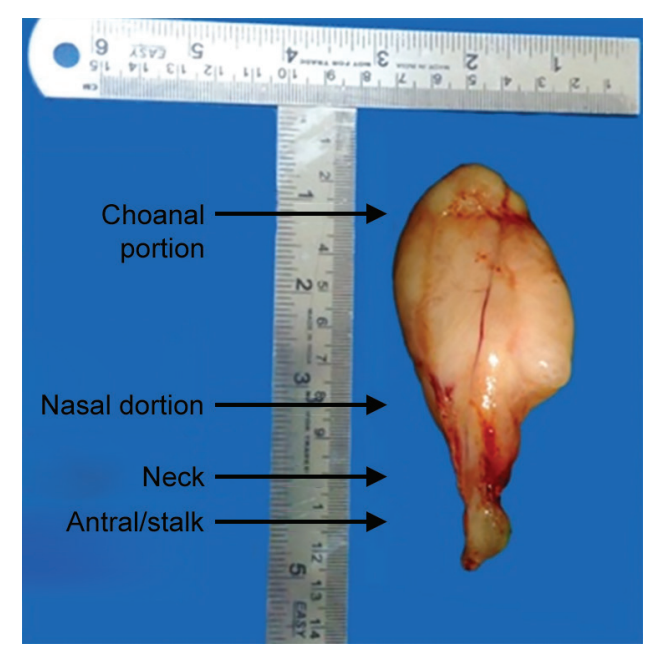

Fig. 1: Antrochoanal polyp specimen (arrows show parts of antrochoanal polyp)
Table 2: Grading of eosinophils in samples examined

\begin{tabular}{lll}
\hline Grading & Frequency & Percentage \\
\hline Occasional cells & 1 & 3.0 \\
Few natural cells & 16 & 48.5 \\
Moderate no. of cells & 5 & 15.2 \\
Clumps & 11 & 33.3 \\
\hline Total & 33 & 100.0 \\
\hline
\end{tabular}

unilateral choanal polyps on an average age of diagnosis is about 27 years.

In our study, the incidence of unilateral nasal polyp on an average age of diagnosis is about 35.5 years.

Nasal polyp has a multifactorial etiology and pathophysiology; one possibility is touching mucous membranes in the narrow osteomeatal complex that results in release of proinflammatory cytokines from the epithelial cells. Another possibility is the influence of special airflow, air current, and pressure in the upper part of the nose. It may be of significance that nerve endings near the borderline between the nose and paranasal sinuses are thin and they easily become damaged due to cytotoxic proteins, released by eosinophils. Chemical, physical, and immunological stimuli causing disturbance of airway epithelium lead to release of proinflammatory cytokines. Most types of nasal polyps have eosinophil as the prevalent inflammatory cell. Immunologically, interleukin (IL)-5 is found in majority of nasal polyp specimens, indicating that IL-5 plays a key role in pathophysiology of an eosinophildominated polyp. Nasal polyp can be considered as a self-perpetuating eosinophil-dominated inflammation; ${ }^{5}$ activated eosinophil further activates and accumulates eosinophils by generating IL-5.

Jeong et $\mathrm{al}^{6}$ did a cohort study and chart review on histological analysis of tissue sections. In 118 patients of nasal polyp, tissue was harvested after endoscopic sinus surgery and histologically analyzed the inflammatory cell population in the nasal polyps. The presence of allergy and asthma was assessed, which was then correlated with the histological findings. On an average, 18.7\% showed eosinophils. The authors suggested a tissue eosinophil proportion of more than $11 \%$ as a criterion for eosinophilic allergic polyp.

In our study, out of 70 patients with unilateral nasal polyp, 47\% (33) showed tissue eosinophil (Figs 2 and 3).

Zhang et $\mathrm{al}^{7}$ in their retrospective study and analysis found 67 eosinophilic nasal polyps patients and $26 \mathrm{lym}$ phocyte nasal polyp patients. Allergic factors, allergens, and nasal anatomic variations were compared between the two groups. This study showed allergic factors are closely related to eosinophilic nasal polyps and nasal anatomical variations are related to formation of lymphocyte 


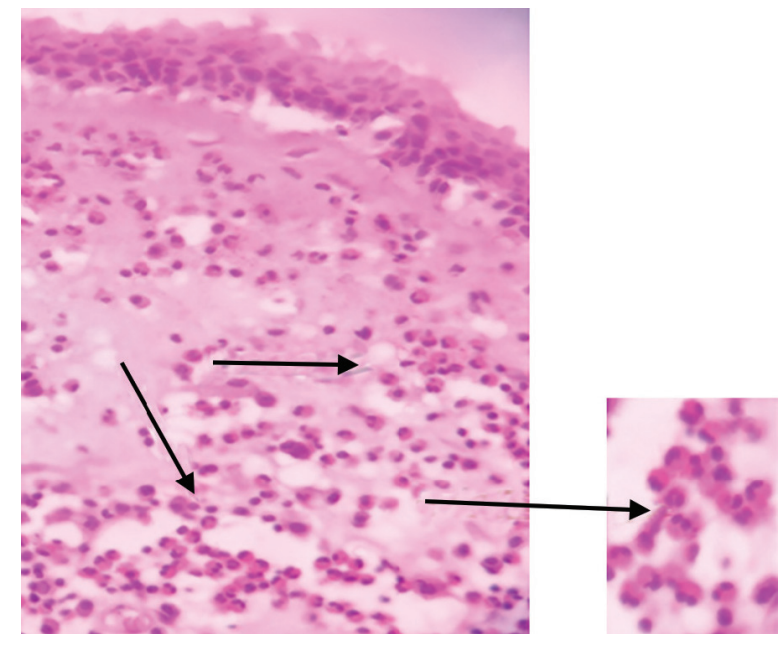

Fig. 2: Histopathology of unilateral nasal polyp showing stromal invasion, predominantly with tissue eosinophil (arrows show eosinophil cells). Hematoxylin and eosin stain with 40x magnification

nasal polyps and different pathogenesis may exist in different pathological types of nasal polyps.

Fan et $\mathrm{al}^{8}$ in their study showed allergic reaction as a risk factor for the accumulation of eosinophils in nasal polyp. T-cell-derived IL-5 and autosecretion of IL-5 from activated eosinophils may be causative reasons for the extension and persistence of eosinophil inflammation. A large proportion of IL-5-producing cells were eosinophils. Eotaxin protein was detected in all tissue samples and dominantly located in epithelial cells. Eotaxin expression between allergic and nonallergic subjects was not significantly different.

Jankowski ${ }^{9}$ in his study showed nasal polyp is histologically characterized by massive edema and accumulation of eosinophils. Immunoglobulin E-mediated allergy plays only a minor role in this, whereas tissue structural cells, i.e., epithelial cells or fibroblasts, could produce cytokines [granulocyte-macrophage colony-stimulating factor (GM-CSF)] and play a role in eosinophil accumulation (microenvironmental theory) and also GM-CSF was mainly produced by eosinophils themselves (autocrine theory), leading to the hypothesis of an intrinsic eosinophilic inflammatory process. Eosinophils may contribute to nasal polyp formation and growth, not only through inflammation but also by exerting their effects on extracellular matrix including stimulation of collagen synthesis.

In our study, 70 patients of unilateral nasal polyp were histologically analyzed for tissue eosinophil, with grading for tissue eosinophil using Shioda and Mishima system. In this grading system, $(++)$ moderate number of cells and $(+++)$ clumps of eosinophils were considered to be significant. Out of 70 patients of unilateral nasal polyp, 33 patients showed tissue eosinophil, and after grading, 16 patients showed significant tissue eosinophil, which shows a strong association of tissue eosinophil

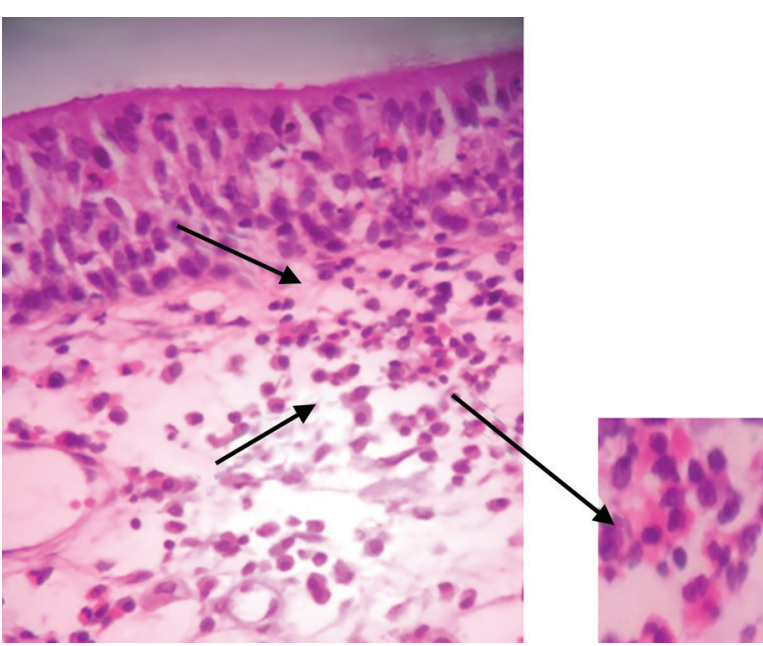

Fig. 3: Histopathology of unilateral nasal polyp showing stromal invasion of inflammatory cells without tissue eosinophil (arrows show inflammatory cells). Hematoxylin and eosin stain with $40 x$ magnification

with unilateral nasal polyp and significance of allergic etiology in unilateral nasal polyp.

The limitation of the study is the need of large sample size.

\section{CONCLUSION}

Since the p-value is significant in our study, otorhinolaryngologists should consider allergy as an etiological factor in the management of unilateral nasal polyp.

\section{REFERENCES}

1. Hedman J, Kaprio J, Poussa T, Nieminen MM. Prevalence of asthma, aspirin intolerance, nasal polyposis and chronic obstructive pulmonary disease in a population-based study. Int J Epidemiol 1999 Aug;28(4):717-722.

2. Santosh UP, Sunil Kumar KB, Pandurangi AS. Clinicopathological correlation between peripheral blood eosinophilia and inferior turbinate tissue eosinophils. AIJOC 2015;1:6-8.

3. Yuca K, Bayram I, Kiroğlu AF, Etlik O, Cankaya H, Sakin F, Kiriş M. Evaluation and treatment of antrochoanal polyps. J Otolaryngol 2006 Dec;35(6):420-423.

4. Larsen $\mathrm{K}$, Tos M. The estimated incidence of symptomatic nasal polyps. Acta Otolaryngol 2002 Mar;122(2):179-182.

5. Gleeson, M; Browning, GG; Burton, MJ, Clarke, R; Hibbert, J; Jones, NS; Lund, VJ; Luxon, LM; Watkinson, JC. Scott Brown's otorhinolaryngology, head and neck surgery. 7th ed. Vol. 2. In: Mygind N, Lund VJ. Boca Raton (FL): CRC Press; 2008. Chapter 121, Nasal polyposis; pp. 1549-1559

6. Jeong WJ, Lee $\mathrm{CH}$, Cho SH, Rhee CS. Eosinophilic allergic polyp: a clinically oriented concept of nasal polyp. Otolaryngol Head Neck Surg 2011 Feb;144(2):241-246.

7. Zhang G, Zhang J, Shi W, Sun P, Lin P. Relationship between allergic factors and eosinophilic nasal polyps. J Clin Otorhinolaryngol Head Neck Surg 2015 Jun;29(12):1098-1100.

8. Fan GK, Wang H, Takenaka H. Eosinophil infiltration and activation in nasal polyposis. Acta Otolaryngol 2007 May;127(5):521-526.

9. Jankowski R. Eosinophils in the pathophysiology of nasal polyposis. Acta Otolaryngol 1996 Mar;116(2):160-163. 